\title{
EL PROBLEMA, ¿ESTÁ EN LA CASA? RELACIONES PERSONALES Y EXCLUSIÓN EDUCATIVA EN LA CIUDAD DE BUENOS AIRES (2001-2010)
}

\author{
Is the Problem at Home? Personal Relations and Educational Exclusion \\ in the City of Buenos Aires (2001-2010)
}

\author{
PABLO DE GRANDE*1 \\ http://orcid.org/0000-0003-1245-1573 \\ * Universidad del Salvador/CONICET, Argentina. \\ Correspondencia: pablodg@gmail.com
}

Recibido: 24-04- 2017

Revisado: 20-06-2017

Aceptado: 20-12-2017

Resumen: En este artículo se analizan los cambios en los condicionantes de la exclusión educativa para la educación media en la Ciudad de Buenos Aires en el período 20012010. A partir de información censal, se estimaron modelos de probabilidades por regresiones logísticas, que permitieron cuantificar el peso relativo de los factores relacionales, individuales y residenciales en las situaciones educativas de los jóvenes de la ciudad. Como principales resultados se destacan la alta variabilidad de las chances de asistencia escolar en función de la relación de los jóvenes con la jefatura del hogar, la sensibilidad a la presencia de niños pequeños en los hogares y la decreciente elasticidad de la asistencia con respecto a las condiciones materiales de hábitat, bienes y servicios de las viviendas.

Palabras clave: exclusión escolar; desigualdad; vulnerabilidad; pobreza.

\begin{abstract}
This article analyzes the evolution of the determinants of exclusion from secondary school in the City of Buenos Aires in the 2001-2010. Using census data, probability models has been estimated using logistic regressions to estimate the weight of relational, individual and residential factors for the educational trajectories for young people in the City of Buenos Aires. As main results highlights: the wide variability of the chances of dropping out in relation to the position of the person in the household; the sensibility of such chances to the presence of babies and toddlers in the households; the decreasing elasticity of the scholar drop out in regard to material conditions of the habitat, services and goods of the households.
\end{abstract}

Keywords: dropout; inequality; vulnerability; poverty.

\footnotetext{
1 Doctor en Ciencias Sociales y Humanidades por la Universidad de Quilmes (Argentina). Licenciado en Sociología por la Universidad de Buenos Aires (Argentina). Colaborador del Centro de Estudios Desigualdades, Sujetos e Instituciones (CEDESI) de la Universidad de San Martín e investigador del Consejo Nacional de Investigaciones Científicas y Técnicas (CONICET). Investigador en temáticas vinculadas con la infancia en el Instituto de Investigación en Ciencias Sociales (IDICSO) y profesor titular en la carrera de Sociología de la Universidad del Salvador (Argentina).
} 


\section{INTRODUCCIÓN}

Este artículo ${ }^{1}$ se inscribe dentro de las investigaciones respecto a la terminalidad de la escuela secundaria en la Ciudad de Buenos Aires. En ellas, muchos interrogantes han quedado planteados luego de constatarse que, tras casi 10 años de obligatoriedad de la escuela secundaria (2002-2010) y de múltiples programas para lograr su universalización, los niveles de participación de los jóvenes en dicho nivel se mantenían constantes (Canevari, Catalá y Montes, 2011).

Buena parte de la bibliografía sobre el tema ha destacado ciertos factores o eventos, tales como la falta de recursos materiales, la necesidad de trabajar o la maternidad o paternidad tempranas (Cubillos Romo, 2017) como elementos que inciden en las posibilidades de un joven de continuar asistiendo a la escuela (Con, 2010; Groisman, 2012). El sentido común de muchos docentes de escuela media señala, como interroga el título de este artículo, que las problemáticas exceden al aula, y que el problema "está en la casa".

La hipótesis de este artículo sostiene que ciertas claves para comprender por qué una significativa cantidad de jóvenes de la Ciudad de Buenos Aires no logra terminar su escuela secundaria se encuentran en la indagación de las tramas de relaciones en que estos se hallan insertos, antes que en factores ecológicos (acceso a servicios públicos, calidad de la vivienda) o monetarios (ingresos laborales, acceso a planes sociales, etc.). Esta línea se encuentra en consonancia con los hallazgos de varios trabajos que, a través de estrategias cualitativas, han observado por ejemplo a la maternidad adolescente como un contexto complejo de responsabilidades y experiencias para los jóvenes involucrados, reparando en las relaciones y sentidos que son puestos en juego y evitando la esencialización de factores o eventos que serían por sí mismos negativos para la continuidad de los estudios u otros proyectos (Del Bono et al., 2017; Fainsod, 2008).

En este artículo buscaremos mostrar, a partir de información censal de los años 2001 y 2010, que la posición relacional ${ }^{2}$ en que se encuentran los jóvenes aparece a lo largo del período como un factor más relevante que los demás aspectos mencionados (vivienda, servicios, bienes materiales), siendo pertinente en consecuencia considerar los apoyos relacionales en forma más explícita y apropiada en las miradas sobre políticas y dinámicas educativas.

\footnotetext{
${ }^{1}$ Esta investigación ha sido financiada por el Consejo Nacional de Investigaciones Científicas y Técnicas de la Argentina (CONICET).

2 Por posición relacional referimos a la configuración de vínculos interpersonales del individuo, es decir, al conjunto de relaciones y círculos con los que habitualmente interactúa y conforma su experiencia cotidiana. Esta noción excede la idea de capital social, pues no refiere al acceso de bienes y servicios de que se dispone por medio de terceros, sino a un modo de organización social y de afrontamiento vital con que el sujeto articula su ser en el mundo.
} 
De sostenerse esta hipótesis antes mencionada, la persistencia de la incapacidad de las políticas escolares para dar acceso a la educación secundaria podría al menos parcialmente explicarse por la distancia que estas mantienen respecto de la heterogeneidad de los soportes vinculares de sus jóvenes: el alumno o la alumna, ¿tiene una familia a su cargo? Su padre, ¿tiene estudios completos? Sus hijos, ¿acceden a jardines maternales para su cuidado? ¿Qué puede —pedagógicamente- ayudar en cada caso?

Incluso si estas indagaciones han comenzado a tener lugar en diseños de programas y políticas públicas, el señalamiento de las distancias entre tales instancias y las tareas directivas y docentes es una constante en las investigaciones en terreno. Cabe preguntarse si una oferta más ajustada a las características de las realidades relacionales de los alumnos podría eventualmente atender mejor a quienes para el año 2010 totalizaban -entre 13 y 21 años - aproximadamente 35 mil personas y se encontraban fuera del sistema educativo, siendo alcanzadas sólo formalmente por la obligatoriedad del ciclo secundario.

El artículo se organiza del siguiente modo: en primer lugar, se resumen antecedentes de investigación respecto de la exclusión escolar en nivel medio. Luego, se presenta la metodología empleada, explicitando las fuentes de información, los criterios aplicados para realizar la segmentación de la población y las herramientas utilizadas para el análisis, así como también se detallan las dimensiones e indicadores que forman parte del trabajo. En tercer lugar se realiza el análisis de los resultados, en dos bloques: uno descriptivo (mapas y cuadros) y uno basado en modelos de regresión logística. Finalmente, en las conclusiones, se retoman las preguntas iniciales a la luz de los resultados obtenidos.

\section{ANTECEDENTES}

La exclusión de jóvenes del sistema escolar es un fenómeno complejo que se ha instalado en las agendas de investigación y gestión educativas. A partir del año 2002, la educación secundaria ha pasado a tener carácter de obligatoria en la Ciudad de Buenos Aires (Con, 2010), y desde el año 2006 esto se ha extendido a la totalidad del país con la promulgación de la Ley de Educación Nacional 26.206 (Ferreyra, Vidales, Kowadlo y Bono, 2013).

La inclusión de este nivel educativo en la formación obligatoria en la Argentina se produjo dentro de un proceso más amplio de búsqueda de expansión de los sistemas educativos nacionales de América Latina (Comisión Económica para América Latina y el Caribe (CEPAL), 2002; Tedesco y López, 2002).

Juan Carlos Tedesco y Néstor López daban cuenta, para el inicio del milenio, de las complejas realidades que los diferentes países de la región enfrentaban a la hora de llevar a la práctica sus pretensiones de universalizar el nivel secundario de enseñanza (Tedesco y López, 2002). Incluso si Argentina, junto a Chile y Uruguay, registraban en el 
año 1995 las tasas más altas de la región ${ }^{3}$, estas comenzaban a encontrar serias dificultades para continuar su camino de mejora hacia una cobertura plena de la población. En el caso del informe de la CEPAL del año 2002, se señalaban como principales factores extra-escolares que incidían en el retiro del ámbito escolar a la escasez de recursos económicos — como vínculo directo o indirecto con "condiciones de pobreza y marginalidad, adscripción laboral temprana, anomia familiar, adicciones, y otros" (Comisión Económica para América Latina y el Caribe, 2002, p. 119) - y a los "problemas familiares" (incluidos allí el embarazo, la maternidad y la ayuda en tareas domésticas).

En la Argentina, los obstáculos para la generalización de este ciclo reconocen en la bibliografía una trama diversa de condicionantes que involucran entre otros la transmisión intergeneracional y residencial de los déficits educativos (Binstock y Cerrutti, 2005; De Grande y Salvia, 2008), el ingreso temprano al mercado laboral (Groisman, 2012), la fragmentación habitacional (Di Virgilio, Marcos y Mera, 2015; Rodríguez, 2009), las experiencias de maternidad adolescente (Fainsod, 2008) y la persistencia de una oferta estatal gratuita pero institucionalmente desarticulada y fragmentaria (Kessler, 2002; Programa de las Naciones Unidas para el Desarrollo, 2009). Esta matriz sostiene, reproduce y articula la desigualdad económica con un acceso segmentado a las credenciales y saberes que la educación tendería a asegurar (Dussel, 2004; Román, 2009).

En línea con este problema, la pobreza ha sido señalada como un elemento vinculado negativamente a las chances de transitar con éxito los distintos ámbitos educativos (Arancibia, 1995; Binstock y Cerruti, 2005; Bourdieu, 2013). Arancibia (1995) reconoce en la bibliografía cuatro niveles de condicionantes estudiados como influyentes en los resultados escolares: el nivel del alumno, el de la familia, el de la escuela y el del profesor. En este artículo nos centraremos en el análisis de los niveles del alumno y de la familia para quienes no asisten, disponiendo gracias a la fuente utilizada de información demográfica detallada.

Es conocido que, durante la primera década del presente siglo, en la Ciudad de Buenos Aires, los niveles de inclusión escolar en la escuela secundaria no se han visto afectados sensiblemente ni por la introducción de su obligatoriedad, ni por los programas de política pública que la acompañaron, ni por el ciclo de reactivación económica que se inició en el período posterior a la devaluación del año 2003 (Groisman, 2012). En este sentido, mientras que la educación primaria mantuvo un nivel de cobertura prácticamente plena (Di Pietro, Tófalo, Medela y Pitton, 2014), en el nivel secundario aún se sostuvo una importante brecha entre quienes inician el ciclo y quienes logran finalizarlo (Con, 2010).

\footnotetext{
3 En el extremo opuesto se encontraban Bolivia, Haití, Honduras y Nicaragua con una tasa de escolarización secundaria agrupada de $32,4 \%$.
} 
En el año 2011, la Dirección de Investigación y Estadística del Ministerio de Educación del Gobierno de la Ciudad de Buenos Aires publicó un informe en el que consignaba el problema como una falla en los mecanismos de inclusión del Estado (Canevari, Catalá y Montes, 2011, p. 4). Sin embargo, dicho informe alterna un enfoque de derechos con el tradicional marco conceptual del "abandono" y la "deserción" escolar. No es menor señalar la fuerte carga de culpabilización de los jóvenes que estos términos imputan —ambos clave en la bibliografía académica sobre exclusión educativa ${ }^{4}$ sugiriendo, en el caso del "abandono", que la escuela es la víctima abandonada por el alumno y, en el caso de la deserción, que la educación sería una "causa" o una "lucha" que los alumnos traicionan (antes que un derecho garantizado por las vías equivocadas ${ }^{5}$.

La perplejidad que la continuidad de los altos niveles de exclusión despierta entre sus analistas se ve reforzada en el hecho de que esta última ocurrió en paralelo con el despliegue de numerosas políticas activas destinadas a su reducción, tales como el programa Fortalecimiento institucional de las escuelas medias, el Programa de becas estudiantiles $^{6}$, el Proyecto de acciones focalizadas en escuelas medias de zonas desfavorables (Con, 2010, p. 5), los programas de retención escolar de alumnas madres o embarazadas y de alumnos padres (Krichesky, 2010) y las Escuelas de Reingreso ${ }^{7}$ (Briscioli y Toscano, 2012; Nobile, 2016).

Así, el período 2001-2010 se caracteriza por la coexistencia de un amplio abanico de políticas públicas focalizadas en la terminalidad de la escuela media con la ausencia de mejoras significativas en la proporción de personas incluidas en dicho nivel: mientras que en el año 2001 había un 13,94\% de personas de 18 años en la Ciudad sin secundario completo no asistiendo a la escuela, en 2010 esa cifra para la misma franja etaria se ubica en $14,84 \% 8$.

\section{OBJETIVOS}

En este contexto, este artículo realiza una caracterización comparada de la población que se encontraba fuera del sistema de educación media en los momentos de inicio y de fin del período 2001-2010, indagando en los aspectos relacionales que es posible identificar a partir de las fuentes censales. Esto organiza los objetos del artículo, que son:

\footnotetext{
${ }^{4}$ Incluyendo mi propia producción del año 2008 (De Grande y Salvia, 2008).

${ }^{5}$ Esta mirada que niega la problemática, responsabilizando a quienes el sistema excluye, se ejemplifica sin matices en la nota del periódico La Nación de junio de 2014 que se titula: "Adultos: sin excusas para no terminar la escuela secundaria" (Polack, 2014).

${ }^{6}$ Según consigna Con, la Dirección de Inclusión Educativa daba cuenta de 44 mil becas otorgadas para el año 2009.

7 Creadas desde el año 2004 en el marco del Programa Deserción Cero.

${ }^{8}$ Elaboración propia en base a Censos Nacionales de Población 2001 y 2010.
} 
1) Explorar si los componentes de la posición relacional de los jóvenes se manifiestan como factores que influyen significativamente en el retiro de la escuela, una vez controlados los aspectos materiales y de acceso a servicios, tales como la calidad de la vivienda, el tipo de barrio o la disponibilidad de agua o gas de red.

2) Identificar tendencias en estos factores, lo que parece pertinente si se considera por una parte el carácter atípico del año 2001 en términos de deterioro social y económico (Fiszbein, Giovagnoli y Adúriz, 2003) y por otro la batería de políticas educativas que fueron implementadas en el período y pudieron haber modificado a la población en situación de exclusión escolar.

Para avanzar en esta dirección, se construyeron tres objetos de análisis con referencia a ambos momentos: una síntesis descriptiva (estadística), un mapa de la distribución de capital educativo y modelos comparables de regresión logística.

La síntesis descriptiva debe permitir situar la incidencia del fenómeno en ambos momentos según variables generales de sexo, estrato y edad.

El mapa de la ciudad según nivel educativo tiene por objeto introducir la distribución espacial del problema para considerar luego los efectos de elementos residenciales entre sus factores.

El modelo de regresión logística tiene por objeto analizar aparición o retiro de factores significativos en las chances de exclusión del sistema escolar, evaluando aquellos caracterizados como "relacionales" bajo el control de los demás factores.

\section{METODOLOGÍA}

\section{Fuentes}

Considerando que la no asistencia es un proceso de interés en una franja etaria específica, y que dentro de ella tiene en la Ciudad de Buenos Aires una incidencia menor al $15 \%$, contar con un relevamiento completo de la población resultaba muy favorable a las posibilidades de análisis y a una mayor robustez de los resultados. Por esta razón se utilizaron para el análisis microdatos de viviendas, hogares y personas de los censos nacionales de población disponibles.

El censo del año 2001 fue realizado en noviembre de dicho año, con un cuestionario único para toda la población. En este censo existieron dificultades derivadas de la negativa del cuerpo docente a participar como censistas, lo que derivó en que fuera llevado a cabo por una planta de personal ad hoc con menor preparación que en ediciones anteriores (Lindenboim, 2011). Para la Ciudad de Buenos Aires, existió a su vez un acceso muy parcial a las zonas de villas y asentamientos ubicadas en la ciudad, las que habían pasado por un proceso de franca expansión durante la década previa. 
El censo del año 2010 fue realizado en el mes de octubre del mismo año. Fue diseñado en dos cuestionarios en paralelo, uno "básico" para aplicar al total de la población y uno "ampliado" para aplicar sobre una muestra del 10\% de los casos. La realización de este censo tuvo lugar en un contexto institucional poco favorable, ya que el organismo de estadística nacional a su cargo se encontraba intervenido por el gobierno nacional, a partir de la "necesidad" de este de controlar los resultados de los cálculos de pobreza e inflación (Isola, 2014; Lindenboim, 2011).

El censo de 2010 ha sufrido numerosas críticas, por problemas de comparabilidad con ediciones anteriores, por la demora en la publicación de sus resultados, así como por numerosas inconsistencias que han sido identificadas por la comunidad académica (Molinatti, 2017) y por el mismo instituto estadístico, incluyendo la duplicación y reubicación de grupos de casos para zonas presumiblemente no censadas (Instituto Nacional de Estadística y Censos, 2016).

En términos generales, la información censal permite (por su carácter exhaustivo y no muestral) una gran apertura de variables manteniendo casos en todas las intersecciones. A esto se agrega la posibilidad de referenciar las unidades mínimas censales (los radios) espacialmente para la construcción de mapas temáticos. En el caso de los censos seleccionados, si bien adolecen de los problemas antes señalados, han sido y continúan siendo una fuente valiosa para el análisis de población de la Ciudad de Buenos Aires.

La cartografía (los polígonos relativos al conjunto de radios) para la representación de las zonas de la ciudad de Buenos Aires fue procurada por la Dirección General de Estadística de la Ciudad de Buenos Aires para el Censo 2010 y por el Instituto Nacional de Estadísticas y Censos para el Censo 2001.

\section{Procedimiento}

El análisis de información fue realizado con las bases de datos de microdatos distribuidas a nivel de radios para los censos de ambos relevamientos. Estas bases fueron recibidas originalmente en formato REDATAM.

A partir de las bases de datos en dicho formato, se realizó la transformación de los datos a un formato de registros individuales utilizando el Conversor Redatam (De Grande, 2016). Sobre los datos resultantes se trabajó el análisis descriptivo y el análisis de regresiones. Los valores para el análisis descriptivo fueron contrastados con las bases de datos REDATAM utilizando R+SP Process, obteniéndose en todos los casos los mismos valores en la base de datos SPSS que en la base de datos REDATAM. 
Los mapas fueron elaborados con el software ArcGIS 10 (ESRI, 2011). Los modelos fueron elaborados utilizando la función de cálculo de regresiones logísticas del paquete SPSS 21 (IBM, 2012) (comando LOGISTIC REGRESSION) ${ }^{9}$.

\section{Estratos residenciales}

Para organizar el análisis de la información, se elaboraron grupos de radios que permitieran distinguir contextos socio-residenciales en diferentes zonas de la Ciudad.

Para ello, se construyeron tres estratos a partir del nivel educativo de los jefes de hogar de los radios ${ }^{10}$, agregando a la tipología un cuarto estrato compuesto por radios ubicados en zonas de alta vulnerabilidad habitacional (asentamientos y villas) con independencia de su nivel educativo.

De este modo, los cuatro grupos de radios que serán presentados en el análisis descriptivo y en los modelos de regresión son:

- Estrato 1. Radios con preponderancia de jefes con estudios terciarios completos o estudios universitarios completos o más. En este grupo aparecen ubicados todos los radios en los cuales el porcentaje de jefes con estudios completos superiores a secundario fue mayor que los porcentajes de jefes en otras categorías.

- Estrato 2. Radios con preponderancia de jefes con nivel educativo de secundaria completa. Con un procedimiento similar al utilizado en el grupo anterior, se identificaron los radios donde el nivel secundario completo (incluyendo en él terciario incompleto y universitario incompleto) fuera el tipo de educación más frecuente entre los jefes.

- Estrato 3. Radios con preponderancia de jefes con nivel educativo menor que secundaria completa. Se agrupó en este estrato a los radios que tuvieran mayoría de jefes sin estudios, con estudios primarios completos 0 incompletos 0 secundarios incompletos.

\footnotetext{
${ }^{9}$ Dado que la estructura de variables utilizada estaba conformada por información de diferentes niveles de agregación (estrato > radio > persona > hogar > individuo), se evaluaron los supuestos de independencia de los datos a nivel de estrato y de radio, utilizando las funciones para Modelos lineales mixtos generalizados (comando GENLINMIXED) de SPSS. En dicha evaluación no resultaron significativos los diferentes esquemas de efectos aleatorios en el nivel 1 del modelo que se introdujeron, por lo que se decidió mantener como herramienta para los modelos las regresiones logísticas binomiales tradicionales del paquete estadístico utilizado.

${ }^{10}$ El radio es uno de los niveles de fraccionamiento en que se descomponen las unidades geográficas en los Censos argentinos recientes. La jerarquía completa es Provincia, Departamento, Fracción, Radio, Segmento, Vivienda, Hogar, Persona. Cada radio reúne grupos de aproximadamente 300 hogares con independencia al tamaño que ocupen, por lo que en cada relevamiento se modifica la diagramación de radios acorde a los desplazamientos y expansiones demográficas ocurridas en el territorio.
} 
- Estrato 4. Radios con alta vulnerabilidad habitacional, coincidentes geográficamente con zonas de villas o asentamientos.

Para la identificación de zonas para el Estrato 4 se utilizó la información ofrecida por la Dirección de Estadísticas y Censos de la Ciudad de Buenos Aires, que publica para el año 2011 un relevamiento cartográfico de Villas y Asentamientos por Comuna ${ }^{11}$. Complementariamente, se consistieron estas zonas con el relevamiento de la organización TECHO (2013).

Dado que ambos relevamientos son posteriores a la realización de los censos utilizados, se excluyeron aquellos asentamientos de menos de 500 hogares o que declararan una antigüedad menor a 20 años (según TECHO, 2013), de modo de imputar a estos espacios zonas que en ambos censos se correspondieran con espacios habitacionalmente precarios. Asimismo, cabe indicar que, si bien para el año 2010 el operativo censal en la Ciudad de Buenos Aires incluyó estrategias específicas para poder acceder a los hogares en villas y asentamientos, esto no fue así en el año 2001, por lo que es conocido que dicho relevamiento subregistra a este grupo poblacional.

\section{Dimensiones, variables e indicadores utilizados en los modelos}

La variable dependiente analizada fue la no asistencia a la escuela cuando ocurría con anterioridad a completar la educación secundaria. Esta situación, en el marco de la obligatoriedad de dicho nivel, plantea una problemática que excede la discusión sobre la desigualdad social e implica un mal funcionamiento del Estado en la generalización de una formación normativamente pautada como obligatoria.

Las dimensiones de control de la no asistencia fueron abordadas a partir de diferentes indicadores, los cuales fueron organizados para el análisis en atributos individuales (tales como la edad o el sexo) y acceso a bienes y servicios de la vivienda (material constructivo, acceso al agua).

A continuación, se describen las variables e indicadores de cada nivel utilizados en el análisis.

\section{Variable dependiente}

No asistencia: a partir de los indicadores de asistencia y nivel educativo alcanzado, se marcó en situación de no asistencia a las personas que, a partir de los 13 años y sin tener el nivel secundario aprobado, no se encontraban asistiendo a una institución educativa en el momento del relevamiento.

\footnotetext{
11 Información accedida en la página de la Dirección de Estadísticas y Censos de la Ciudad de Buenos Aires del Gobierno de la Ciudad de Buenos Aires, el 23/05/2015 desde

http://www.buenosaires.gob.ar/areas/hacienda/sis_estadistico/cartografia.php
} 


\section{Variables explicativas}

Relación con la jefatura de hogar: estrechamente vinculada con la estructura del hogar, este indicador da cuenta del rol desempeñado por el niño o joven dentro de su espacio doméstico. Si bien rara vez es indagado en forma desagregada, es esperable que las variaciones en este indicador se encuentren asociadas a cambios sustanciales en las realidades cotidianas, en la medida que refleja posiciones tan disímiles como ser hijo del jefe de hogar, o ser la pareja del jefe de hogar (en ausencia presumible de otros adultos), o ser parte del personal de servicio doméstico de la familia, entre otros.

Ocupación: el indicador de ocupación permite evaluar la relación entre la participación en el mercado de trabajo y la continuidad de los estudios. Las cualidades de la ocupación (tal que si se trata de un trabajo de tiempo completo o parcial, o si ocurren en una modalidad registrada o informal, o la rama de actividad involucrada) no fueron indagadas en la medida en que se encontraban disponibles en las bases del Censo de 2001 pero no en las del Censo de 2010.

Con niños de hasta 5 años: la presencia de niños pequeños busca dar cuenta de cargas de cuidado que puedan estar presentes en el hogar en función de maternidades o paternidades recientes. Si bien el Censo de 2001 pregunta por la cantidad de hijos nacidos vivos para cada persona (pudiéndose establecer con mayor certeza quiénes son la madre y el padre de los niños en el hogar) esta pregunta no fue repetida en el cuestionario básico de 2010, razón por la que se construyó para remitir a estas situaciones un indicador a nivel del hogar que resume la cantidad de niños pequeños habitando allí, sin distinguirse si el niño es hijo o no de quienes estén en condiciones de asistir a la escuela secundaria y no lo hagan.

Hogar monoparental: la ausencia de un cónyuge para llevar adelante el sostenimiento del hogar ha sido señalada en la bibliografía como un factor de riesgo respecto de chances de continuidad educativa de los hijos. Se contrastó esta hipótesis en ambos cortes temporales y a lo largo de la segmentación de estratos.

Jefatura femenina: si bien la jefatura femenina se encuentra con frecuencia asociada a la monoparentalidad (padres varones ausentes), se evaluó su influencia en forma separada.

Jefe inactivo y al menos un adulto inactivo: estos indicadores procuran dar cuenta de la existencia de personas no insertas en el mercado de trabajo como factor de menor integración de los hogares, distinguiendo jefes de adultos en general ( $>=18$ años). Si bien las situaciones que conducen a la inactividad pueden ser muy diversas (estudios, 
enfermedad, ocupaciones domésticas, jubilación, entre otros), su presencia ofrece una medida general de la relación entre los adultos del hogar y el mercado de trabajo.

Nivel educativo del jefe: el máximo nivel educativo alcanzado fue clasificado en cuatro categorías, agrupando:

- Jefe sin instrucción. Esta categoría incluyó a hogares cuyo jefe consignara tener un nivel educativo de primaria incompleta o menos.

- Jefes con primaria aprobada. Este grupo incluyó a hogares con jefes con educación primaria aprobada o secundaria cursada en forma incompleta.

- Jefes con secundaria completa. En esta categoría quedaron comprendidos los jefes con secundaria completa, así como también aquellos que hubieran iniciado estudios terciarios o universitarios sin haberlos completado.

- Jefes con nivel terciario o universitario o más aprobados. En este grupo fueron clasificados aquellos hogares cuyo jefe hubiera completado un nivel de educación superior, ya sea en ámbitos de educación terciaria o universitaria.

Proporción de jóvenes en situación de no asistencia en el radio (entre 0 y 1): en relación a la influencia del barrio, además de la separación por estratos residenciales, se ha explorado qué indicadores podían permitir marcar diferencia al interior de estos estratos. De los evaluados, solamente el alto nivel de no asistencia de los demás jóvenes del barrio operó como un factor autónomo respecto de las demás variables produciendo un aumento en las chances de exclusión de los jóvenes.

Variables de control

\section{Atributos individuales}

Los indicadores utilizados en el nivel individual fueron:

Edad: se incorporó la edad como criterio de recorte para el análisis, utilizando la franja de personas de entre 13 a 21 años inclusive. Si bien la edad de finalización del secundario, en caso de aprobarse en forma continua todo el ciclo educativo, son los 18 años, a la luz de diversas políticas ya mencionadas que estuvieron orientadas a la incorporación de población que excediera ese rango, pareció pertinente extender el período de observación hasta los 21 años. 
Sexo: para los diferentes espacios investigados (de contextos residenciales y de cortes intercensales) se buscó indagar las dependencias entre la no asistencia y la adscripción de género a partir del indicador "sexo" de ambos censos.

\section{Condiciones materiales (hábitat, bienes y servicios)}

Los bienes y servicios a los que tiene acceso el hogar, así como la calidad constructiva de la vivienda, fueron operacionalizados a partir de los siguientes indicadores:

Ausencia de cañería de agua en la vivienda: este indicador representa un rasgo clave de la calidad constructiva, y especifica si el hogar cuenta con una instalación de caños para la distribución del agua dentro de la vivienda. Esto se encuentra asociado a la disponibilidad de un baño con descarga y de agua potable de red al interior de la vivienda, de los cuales no suele disponerse sin este tipo de infraestructura.

No se dispone de gas de red: para evaluar esta disponibilidad de servicio en el hogar, que afecta tanto a las necesidades de calefacción como de preparación de alimentos, se utilizó el indicador referido a principal combustible utilizado para cocinar en la vivienda.

No hay computadora en el hogar: este indicador registra la capacidad económica y el capital cultural vinculado a la tenencia de una computadora. En el transcurso de la década se observa un crecimiento de este indicador, incluso si los programas llevados adelante en la Ciudad de Buenos Aires de políticas de inclusión digital donde se distribuyeron computadoras a alumnos en los niveles primario y secundario se desarrollaron con posterioridad -en el plano nacional el programa Conectar Igualdad (Gigli Box, 2014) y, en el ámbito de la ciudad, el Plan Sarmiento-.

No posee heladera: si bien la incidencia de este indicador es baja en la distribución general $(2,7 \%$ de los hogares), permite tener una referencia de aquellos hogares con serias dificultades para acceder a bienes básicos de la organización doméstica, ascendiendo a $4,8 \%$ de los hogares en el estrato 3 y a $20,4 \%$ en el estrato 4 .

No ser propietario de la vivienda y del terreno: esta característica de la vivienda procura diferenciar las condiciones de estabilidad propia de quienes son dueños de la vivienda y del terreno en comparación con quienes no lo son. Sea en las situaciones de préstamo, inquilinato, propiedad parcial u ocupaciones irregulares, resulta posible que la mayor precariedad en el régimen de tenencia pueda traducirse en un aumento de la vulnerabilidad educativa. 
Ausencia de cielorraso: este ítem indica un grado intermedio de precariedad de la vivienda. La disponibilidad de cielorraso es un indicador de madurez de la construcción, teniendo su ausencia un impacto usualmente directo en la calidad de vida en virtud del rol de aislación del cielorraso respecto de temperaturas extremas del exterior en verano e invierno.

\section{Variables no incluidas en los modelos finales}

Además de conocerse los factores identificados como condicionantes en los modelos de regresión logística, resulta conveniente especificar al menos brevemente qué variables fueron exploradas sin resultados exitosos. Si bien la falta de significatividad de un factor no permite afirmar la imposibilidad de identificarlo como relevante a través de otra medida, se ha considerado pertinente enumerar las variables e indicadores que fueron incluidos en diferentes pruebas en modelos alternativos y fueron finalmente descartados de los modelos finales debido a su escasa o nula significatividad o por su alta correlación con otros indicadores.

- Atributos individuales: edad, sexo, migración (nacido en país limítrofe).

- Estructura y situación socioeconómica del hogar: tamaño del hogar (cantidad de personas); migración (jefe nacido en país limítrofe); hogar de tipo unipersonal; adultos con estudios secundarios completos; adultos con estudios universitarios completos.

- Condiciones materiales (hábitat, bienes y servicios): hogar con pisos de calidad deficiente; hogar con cubierta del techo de calidad deficiente; ser propietario de la vivienda, pero no del terreno; habitar en condición de hacinamiento ( 3 o más personas por habitación).

- Contexto residencial: tasa de desocupación del radio; tasa de actividad del radio; promedio de edad de los jefes del radio; \% de jóvenes (13-21) en el radio; \% de hogares con caños de agua dentro de la vivienda; \% de hogares con pisos de calidad deficiente; \% de hogares que no disponen de gas de red para cocinar.

\section{ANÁLISIS DESCRIPTIVO}

\section{Indicadores generales}

La cantidad total de hogares en la Ciudad de Buenos Aires en el año 2010 era de 1.150.732, siendo 310.427 la cantidad de jóvenes en la franja etaria de los 13 a los 21 años. 
En la Figura 1, resaltan en primer lugar las transiciones entre estratos por nivel educativo que se registraron en esta década, llegando los jefes con universitario o terciario completos a constituir un $30,85 \%$ de los hogares. En este aspecto, se observa un aumento cuantitativo muy significativo de la cantidad de personas que habitan en radios donde el nivel universitario es el más frecuente, duplicándose para el año 2010 respecto a la cifra del año 2001.

En segundo lugar, se destaca la caída en las tasas de desempleo en el período indicado, baja que se materializó en todos los estratos, pasando el nivel general de desocupación de 18,86\% a 4,29\%, y mejorando sensiblemente la situación en el estrato de villa o asentamientos, donde en el año 2001 el desempleo abierto alcanzaba al 34,4\% de las personas activas.

En tercer lugar, en el nivel de las condiciones materiales, el indicador con más movilidad fue la tenencia de computadoras, reduciéndose notoriamente la cantidad de hogares sin computadora, descendiendo de $52 \%$ a $26,56 \%$ en la distribución general y de $93,38 \%$ a $74,69 \%$ en el estrato más bajo. Otros demás indicadores, como la disponibilidad de gas de red en los estratos más bajos o la carencia de heladera en aproximadamente el 15\% de los hogares de este estrato, registran variaciones menores (inferiores a 2pp.) en el período observado.

\section{Inclusión educativa}

Al observar la evolución de la estadística educativa a partir de la información intercensal se confirma, en primer lugar, que el período 2001-2010 ha tenido muy escaso impacto en la mejora de los rendimientos educativos de la población de la Ciudad de Buenos Aires en términos de asistencia en el nivel medio, habiendo pasado la media de no asistencia general de 11,44\% a 11,31\% (Figura 2). En 2010, sobre un total de 310 mil personas de entre 13 y 21 años, esta cifra indica que 35 mil jóvenes se encontraban sin asistir a la escuela no habiendo completado el nivel secundario.

En segundo lugar, en la distribución por edad se advierte que para 2010 la franja de 16 y 17 años muestra una agudización de la incidencia de la no asistencia, llegando esa cifra a 12,17\% (2pp. por encima del valor observado en 2001).

Inversamente, cabe señalar que la no asistencia tardía que se observaba en la información de 2001, donde a los 20 y 21 años continuaba aumentando el número de personas que abandonaba la educación secundaria -en situaciones de rezago- no se presenta ya en 2010, estabilizándose la cifra a partir de los 19 años de edad levemente por debajo del 17\%. 
Figura 1. Indicadores de la población total seleccionados según distribución general y estratos residenciales. CABA. Años 2001-2010

\begin{tabular}{|c|c|c|c|c|c|c|c|c|c|c|}
\hline \multirow{3}{*}{ Ciudad de Buenos Aires } & \multicolumn{2}{|c|}{ General } & \multirow{2}{*}{\multicolumn{4}{|c|}{$\frac{2001}{\text { Estrato }}$}} & \multirow{2}{*}{\multicolumn{4}{|c|}{$\frac{2010}{\text { Estrato }}$}} \\
\hline & \multirow{2}{*}{2001} & \multirow{2}{*}{2010} & & & & & & & & \\
\hline & & & E1 & E2 & E3 & E4 & E1 & E2 & E3 & E4 \\
\hline Total de población & 2.725 .094 & 2.828 .423 & 115.198 & 984.668 & 1.261 .953 & 363.275 & 155.243 & 346.259 & 1.577 .596 & 749.325 \\
\hline Total de población 13 a 21 años & 333.350 & 310.427 & 19.531 & 125.383 & 145.597 & 42.839 & 28.645 & 46.522 & 162.547 & 72.713 \\
\hline Total de hogares & 1.024 .231 & 1.150 .732 & 28.713 & 338.648 & 508.891 & 147.979 & 45.517 & 116.382 & 653.732 & 335.101 \\
\hline \multicolumn{11}{|l|}{ Individual (\%) } \\
\hline Género (varón) & 45,41 & 46,07 & 49,69 & 46,45 & 44,70 & 43,71 & 49,59 & 47,76 & 46,01 & 44,70 \\
\hline \multicolumn{11}{|l|}{ Edad } \\
\hline - 0 a 12 años & 14,70 & 14,46 & 32,55 & 15,83 & 13,09 & 11,53 & 28,24 & 18,29 & 13,52 & 11,83 \\
\hline - 13 a 16 años & 4,85 & 4,26 & 7,60 & 5,33 & 4,43 & 4,17 & 7,55 & 5,63 & 4,04 & 3,39 \\
\hline - 17 a 21 años & 7,38 & 6,72 & 9,36 & 7,40 & 7,11 & 7,62 & 10,90 & 7,80 & 6,26 & 6,32 \\
\hline - 22 a 49 años & 40,01 & 41,78 & 43,13 & 38,59 & 40,97 & 39,57 & 44,58 & 39,72 & 41,90 & 41,91 \\
\hline - 50 a 69 años & 20,79 & 21,24 & 6,10 & 20,68 & 21,46 & 23,40 & 7,49 & 18,94 & 22,12 & 23,31 \\
\hline - 70 y más & 12,27 & 11,54 & 1,26 & 12,17 & 12,94 & 13,70 & 1,24 & 9,61 & 12,16 & 13,25 \\
\hline \multicolumn{11}{|l|}{ Condición de actividad } \\
\hline - Ocupado* & 81,14 & 95,71 & 65,60 & 76,83 & 83,39 & 88,05 & 93,07 & 94,18 & 95,79 & 96,60 \\
\hline - Desocupado* & 18,86 & 4,29 & 34,40 & 23,17 & 16,61 & 11,95 & 6,93 & 5,82 & 4,21 & 3,40 \\
\hline - Inactivo** & 47,90 & 38,89 & 54,86 & 50,48 & 45,94 & 45,54 & 49,57 & 44,08 & 38,03 & 36,11 \\
\hline \multicolumn{11}{|l|}{ Relación con la jefatura de hogar } \\
\hline - Es el jefe & 37,59 & 40,68 & 24,92 & 34,39 & 40,33 & 40,73 & 29,32 & 33,61 & 41,44 & 44,72 \\
\hline - Conyuge o pareja & 20,12 & 20,10 & 16,86 & 20,08 & 20,39 & 20,28 & 16,44 & 18,45 & 20,48 & 20,81 \\
\hline - Yerno o nuera & 0,55 & 0,54 & 0,76 & 0,84 & 0,40 & 0,24 & 0,88 & 1,06 & 0,52 & 0,26 \\
\hline - Otros (familiares y no familiares) & 7,20 & 6,90 & 9,88 & 7,47 & 7,14 & 5,83 & 8,83 & 7,96 & 6,90 & 6,03 \\
\hline - Servicio domestico & 0,53 & 0,38 & 0,04 & 0,14 & 0,38 & 2,27 & 0,02 & 0,06 & 0,19 & 1,00 \\
\hline - Hijo y nieto & 34,01 & 31,39 & 47,54 & 37,08 & 31,36 & 30,64 & 44,52 & 38,85 & 30,47 & 27,18 \\
\hline \multicolumn{11}{|l|}{$\begin{array}{l}\text { Estructura y situación } \\
\text { socioeconómica del hogar }(\%) \\
\text { Educación del jefe }\end{array}$} \\
\hline - Sin instrucción & 6,34 & 4,56 & 29,60 & 7,60 & 4,37 & 2,43 & 21,63 & 8,82 & 3,37 & 1,56 \\
\hline - Primaria & 33,43 & 26,00 & 52,41 & 45,70 & 27,61 & 14,36 & 52,20 & 46,91 & 25,32 & 12,35 \\
\hline - Secundaria & 36,09 & 38,59 & 16,55 & 33,18 & 40,73 & 34,09 & 24,25 & 33,70 & 42,77 & 35,03 \\
\hline - Terciaria o universitaria & 24,13 & 30,85 & 1,44 & 13,52 & 27,29 & 49,12 & 1,91 & 10,58 & 28,55 & 51,06 \\
\hline Niños $<=5$ años en el hogar & 23,07 & 22,87 & 56,47 & 25,29 & 20,07 & 16,92 & 49,45 & 30,37 & 20,96 & 17,89 \\
\hline Jefatura femenina & 28,95 & 36,23 & 27,26 & 26,72 & 30,62 & 29,73 & 43,59 & 35,75 & 35,91 & 35,60 \\
\hline Hogar monoparental & 21,62 & 22,95 & 21,48 & 21,18 & 21,99 & 21,59 & 27,63 & 25,84 & 22,58 & 21,43 \\
\hline Hay adultos inactivos en el hogar & 56,56 & 40,80 & 50,91 & 61,03 & 53,67 & 56,30 & 46,02 & 47,56 & 40,04 & 38,19 \\
\hline Jefe desocupado & 9,38 & 1,94 & 23,40 & 11,11 & 7,99 & 5,11 & 4,20 & 2,48 & 1,81 & 1,49 \\
\hline Jefe inactivo & 23,53 & 17,80 & 14,72 & 24,99 & 23,29 & 23,16 & 16,35 & 19,28 & 17,79 & 17,45 \\
\hline \multicolumn{11}{|l|}{$\begin{array}{l}\text { Condiciones materiales (hábitat, } \\
\text { bienes y servicios) }(\%)\end{array}$} \\
\hline Ausencia de cañería de agua en la & 1,90 & 2,23 & 13,89 & 2,10 & 1,16 & 0,17 & 11,56 & 4,00 & 1,78 & 0,43 \\
\hline Ausencia de cielorraso & 6,86 & 12,27 & 69,95 & 6,73 & 2,76 & 1,43 & 65,15 & 19,78 & 8,78 & 5,19 \\
\hline No hay computadora en el hogar & 52,00 & 26,56 & 93,38 & 59,92 & 47,46 & 33,19 & 74,69 & 40,36 & 24,29 & 15,01 \\
\hline No se dispone de gas de red & 7,32 & 9,81 & 93,48 & 6,53 & 1,98 & 0,70 & 93,69 & 16,66 & 3,48 & 2,58 \\
\hline No se posee heladera & 2,41 & 2,23 & 14,13 & 2,54 & 1,78 & 0,54 & 15,21 & 3,54 & 1,51 & 0,43 \\
\hline No propietario de vivienda y terreno & 67,44 & 57,43 & 40,45 & 66,95 & 68,32 & 74,29 & 49,58 & 54,36 & 57,04 & 61,29 \\
\hline
\end{tabular}

Fuente: elaboración propia en base a datos del CNPHyV 2001 y CNPHyV 2010.

* Calculados sobre la población económicamente activa (PEA).

** Calculado sobre el total de la población. 
La distribución por género, por su parte, no ha mostrado variaciones de importancia en el periodo intercensal, siendo en ambos momentos 2pp. mayor la no asistencia escolar agregada para varones que para mujeres.

Figura 2. No asistencia y cantidad de población según sexo, edad y estrato (13 a 21 años). CABA. Años 2001-2010

\begin{tabular}{|c|c|c|c|c|}
\hline & \multicolumn{2}{|c|}{2001} & \multicolumn{2}{|c|}{2010} \\
\hline & No asistencia (\%) & Población total & No asistencia (\%) & Población total \\
\hline \multicolumn{5}{|l|}{ Género } \\
\hline - Varón & 12,66 & 165.517 & 12,52 & 153.888 \\
\hline$\cdot$ Mujer & 10,23 & 167.833 & 10,11 & 156.539 \\
\hline \multicolumn{5}{|l|}{ Edad } \\
\hline$\cdot 13$ años & 1,64 & 32.411 & 2,74 & 28.596 \\
\hline$\cdot 14$ años & 3,52 & 32.912 & 2,27 & 31.056 \\
\hline$\cdot 15$ años & 5,19 & 33.402 & 3,10 & 30.678 \\
\hline$\cdot 16$ años & 8,17 & 33.568 & 9,72 & 30.038 \\
\hline$\cdot 17$ años & 10,24 & 34.176 & 12,17 & 30.768 \\
\hline$\cdot 18$ años & 13,94 & 36.796 & 14,84 & 35.109 \\
\hline - 19 años & 16,08 & 40.670 & 16,55 & 38.771 \\
\hline - 20 años & 18,32 & 42.819 & 16,89 & 42.550 \\
\hline$\cdot 21$ años & 19,22 & 46.596 & 16,75 & 42.861 \\
\hline \multicolumn{5}{|l|}{ Estrato } \\
\hline - E1. Villa o asentamiento & 38,36 & 19.531 & 29,88 & 28.645 \\
\hline - E2. Sólo primaria & 14,09 & 125.383 & 18,05 & 46.522 \\
\hline - E3. Sólo secundaria & 7,79 & 145.597 & 9,14 & 162.547 \\
\hline - E4. Universitaria o más & 3,83 & 42.839 & 4,51 & 72.713 \\
\hline Total & 11,44 & 333.350 & 11,31 & 310.427 \\
\hline
\end{tabular}

Fuente: elaboración propia en base a datos del CNPHyV 2001 y CNPHyV 2010.

\section{Contexto residencial}

La segmentación por estratos socioeducativos, como era de esperar, mostró una correlación positiva con los niveles de no asistencia de los jóvenes, alcanzando el 29,88\% de los casos en el estrato 1 (zonas con villas y asentamientos) en el año 2010.

Sin embargo, puede considerarse alentador el hecho de que los valores en 2001 hayan mostrado una polarización aún mayor, llegando en el estrato más vulnerable la no asistencia a $38,36 \%$.

En la cartografía por estrato se observa el patrón de segregación educativo nortesur característica del desarrollo histórico de la Ciudad de Buenos Aires, con una importante concentración en los barrios ubicados hacia el norte (Belgrano, Palermo, Recoleta) de los radios con mayor capital educativo (Mapa 1).

Asimismo, la comparación 2001-2010 permite caracterizar la morfología de los cambios acontecidos en estos grupos de segmentación socioeducativa. 
En ella, primeramente, se ve reflejada la importante disminución de radios en los cuales eran mayoritarios los jefes solamente con primaria completa.

Mapa 1. Distribución de radios según estratos (grupos) de prevalencia de nivel educativo alcanzado del jefe de hogar. CABA. Años 2001-2010
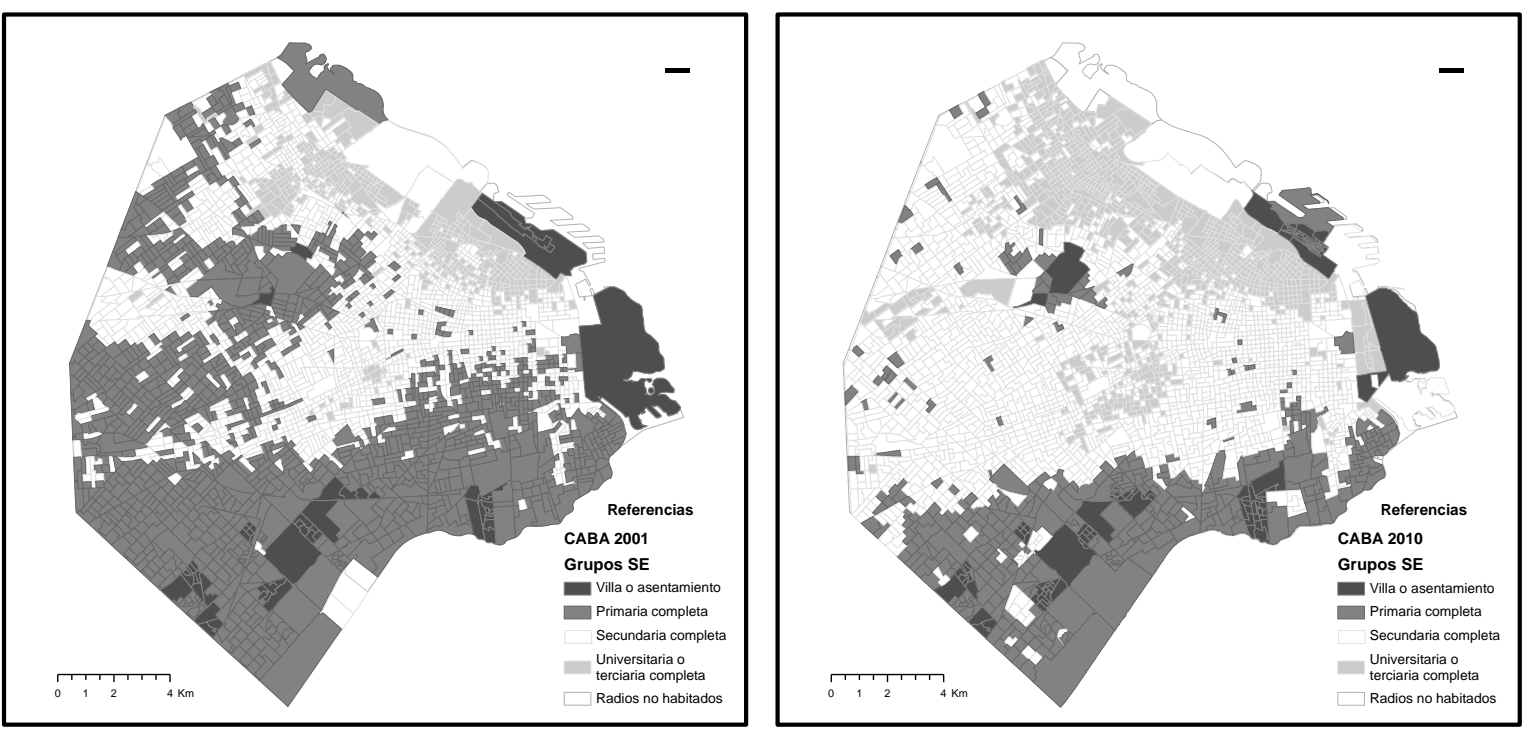

Fuente: Elaboración propia en base a datos del CNPHyV 2001 y CNPHyV 2010.

En términos de barrios, aquellos con mayores transiciones hacia el estrato 4 (jefes terciarios y universitarios) fueron Caballito, Devoto, Colegiales y Nuñez.

En las transiciones del estrato 2 hacia el estrato 3 (de mayoría de jefes con primaria a mayoría de jefes con secundaria) se destaca el grupo de barrios localizados entre las zonas de Liniers y Villa del Parque: Versalles, Villa Real, Villa Luro, Vélez Sarsfield, Floresta, Villa Santa Rita, Monte Castro. También experimentaron esta transición buena parte de los barrios de Villa Pueyrredón, Paternal y Parque Chas. En el sureste de la Ciudad esto ocurrió también en los barrios al sur de Almagro y Balvanera, a saber, Boedo, Parque Patricios, San Cristóbal, pasando ellos casi en su totalidad a integrar sus radios en el estrato 3 (mayoría de jefes con secundario completo en comparación a las demás categorías).

\section{REGRESIONES}

Los modelos de regresión que se exploraron en la etapa de investigación buscaron responder en primer lugar a la pregunta respecto de en qué medida podía considerarse que los indicadores vinculados a las posición relacional tenían mayor preeminencia sobre el fenómeno de la exclusión escolar que otras dimensiones más conocidas. 
En segundo lugar, se indagó respecto de si los condicionantes de la exclusión escolar han encontrado un régimen diferente de funcionamiento en el final de la primera década del 2000 (es decir, en la comparación 2001-2010) o si, por el contrario, esta estructura de condicionantes observables se mantuvo estable.

En la Figura 3 se observan las razones de momios (odds ratios ${ }^{12}$ ) de los modelos de regresión elaborados. Estos coeficientes cuantifican las diferencias en las chances de abandonar la escolarización introducidas para cada una de las variables especificadas. Las lecturas de resultados se basan en las variaciones que estas razones indican, en tanto un aumento en el factor implica un aumento proporcional en las chances de ocurrencia de la no asistencia escolar.

Por ejemplo, si la fila que corresponde a la variable "no hay computadora en el hogar" tiene para su razón de momio $(\operatorname{Exp}(B))$ un valor igual a 2,402 para el año 2001, se interpreta que las chances de abandonar de quienes no disponen de computadora es 2,402 veces más grande que las chances de quienes sí tienen. De igual modo, si dicho valor fuera 0,5 se interpretaría que las chances de abandonar serían la mitad que las de quienes sí tienen. A continuación se analizan cada una de las variables involucradas en el modelo, tanto para el comportamiento de las variables explicativas como de las variables de control.

\section{Variables explicativas}

Al igual que en los casos anteriores, encontramos en los espacios de mayor nivel educativo un más alto grado de diferenciación según, en este caso, variables materiales. La no tenencia de computadora llega así a representar un cambio de 2,397 veces en las chances de no asistencia en el estrato 4.

En el caso de la condición de actividad, las correlaciones fueron aún más marcadas: mientras que estar ocupado multiplicó por 2,345 las chances de dejar la escuela, estar buscando trabajo lo hizo en 2,228 veces. Esta primera aproximación da cuenta de una importante dependencia entre la situación laboral del niño o joven y la trayectoria educativa.

Respecto del rol en el hogar, si bien afrontar las cargas de ser jefe del hogar aumentó las chances en forma significativa respecto de desempeñar el rol de hijo o de nieto $^{13}$, fue el desempeñar los demás roles analizados donde se observó un mayor

\footnotetext{
12 Un odd, o un momio, o 'chance', es una probabilidad expresada en la forma de cantidad de casos positivos sobre una cantidad de casos negativos. De este modo, por ejemplo, las chances (dando un valor al azar) de los varones de 3 años de asistir al jardín sería una probabilidad expresada en la forma de que cada 3 chicos que asisten, 2 no asisten. O como coeficiente, las chances de asistir serían de 1,5 (es decir, 3 / 2). Este valor es diferente a la probabilidad distribuida de 0 a 1, que para el mismo escenario daría 0,6 (cada 10 chicos, 6 asisten). Si la cantidad de eventos negativos es mayor a los positivos, las chances se vuelven menores a 1, dado que si por ejemplo cada 2 chicos que asisten, 3 no lo hacen, el valor del coeficiente será de 0,66 (es decir 2 / 3).

13 Nieto e hijo fueron tratadas conjuntamente debido a que, controlando por los demás factores, no mostraron diferencias significativas entre sí para ninguno de los estratos ni para la muestra general.
} 
impacto. Mientras que ser jefe aumentó en un $70,4 \%$ las chances de abandonar la escuela, ser cónyuge o pareja del jefe (es decir, ser la pareja presumiblemente de un jefe o jefa joven) multiplicó - siempre para 2010 - por 4,324 dichas chances. En el caso del empleo doméstico sin retiro - es decir, de las personas de entre 13 y 21 años que fueron censadas en las casas de sus empleadores por trabajar en la modalidad de servicio doméstico sin retiro (o "con cama") o ser familiares de alguien trabajando en esta condición- las chances de no asistencia se multiplicaron por 12,7. Esto da cuenta para dichos casos de una situación de extrema precariedad en términos educativos, especialmente si se considera que cada factor de la regresión aporta su peso independiente, es decir que esta asignación de rol es adicional al aporte hecho por la condición de actividad y la edad.

En los valores de las chances según indicadores individuales por estrato, resulta llamativa la concentración de valores más altos para sexo y ocupación en los estratos de mayor nivel educativo (estratos 3 y 4). En otras palabras, que fue en los radios donde la educación terciaria o universitaria completa de los jefes fue el nivel educativo de mayor frecuencia donde se constató el valor máximo de influencia de la participación laboral, llegando a ser 2,8 veces más grandes las chances de no asistencia de quienes trabajaban respecto de quienes se lograban mantener fuera del mercado de trabajo.

Inversamente, el desempeñar la jefatura del hogar en estos espacios de mayor nivel educativo tuvo un peso menor al que mostró en los espacios de menores recursos, siendo su valor 2,541 en el estrato más bajo y 1,296 en el estrato más alto.

Para el caso del servicio doméstico con cama, fue en las zonas con prevalencia de jefes con terciario o universitario completo (estrato 4) donde más se vieron deterioradas las chances de inclusión educativa en comparación con los demás niños y jóvenes de estos barrios, siendo 20 veces mayor las chances de abandonar la escuela para los miembros del servicio doméstico "con cama" que para los hijos y nietos de jefes de dichos espacios.

Al comparar la situación de los condicionantes individuales en el año 2010 con los resultados de los modelos realizados con la información censal del año 2001, se advierten en términos generales bajas en los niveles de correlaciones entre ellos y las chances de no asistencia. Si bien esto no significa que tales dependencias hubieran desaparecido o estén cerca de desaparecer, mientras que las chances de abandonar en función de estar ocupado aumentaban 3,058 veces en 2001, en el año 2010 lo hacen en razón de 2,345 veces. Esto ocurre también como tendencia desagregada al observarse la apertura por estrato, con algunas excepciones, tal como lo son el aumento en el estrato más bajo del peso de la masculinidad en las chances de no asistencia (en 2001 era de 1,157 en relación a las mujeres, mientras que en 2010 pasa a 1,350) y el descenso muy marcado también en el estrato más bajo de las chances de no asistencia de las parejas de los hijos del jefe (categoría yerno o nuera) respecto de los hijos y nietos propios, el cual pasa de 6,287 veces a 3,201 veces. 
El principal factor dentro de los que organizan la influencia de la estructura familiar y sus capacidades en las chances de completar los estudios secundarios en el año 2010 ha sido la transmisión intergeneracional, es decir, el nivel de instrucción del jefe de hogar: mientras que para quienes cuentan con jefes de hogar con secundaria completa las chances de no asistencia crecen un $23,4 \%$ respecto de quienes cuentan con jefes de más educación, para quienes tienen jefes sólo con educación primaria tales chances aumentan en forma muy marcada, creciendo en un 382,2\%.

Cabe señalar que el segundo factor en importancia en este sentido ha sido la existencia en el hogar de niños pequeños (de hasta 5 años), dando una medida tangible de las necesidades de atención y recursos que los niños en estas edades redirigen hacia ellos. En este aspecto, la presencia de niños pequeños en el hogar ha aumentado en $79,8 \%$ las chances de no asistencia de quienes habitaban con ellos en el año 2010.

En la vista por modelos parciales por estrato, se destaca el mayor impacto que tienen en los estratos más altos (E3 y E4) los factores recién descriptos. Tanto el bajo nivel educativo de los padres como la presencia de niños en el hogar hacen sentir su efecto con más fuerza mientras aumenta el capital educativo de la zona de residencia, llegando la influencia en las chances de no asistencia de habitar con un jefe sin instrucción a 4,843 veces (en relación a uno con estudios universitarios o terciarios), mientras que el cuidado de niños pequeños produce chances 2.398 veces mayores para quienes conviven con ellos cotidianamente en dicho estrato. La monoparentalidad y la inactividad de adultos en el hogar, en cambio, no muestran asociaciones claras con el eje de la estratificación, asociándose en forma leve y con más centralidad en el estrato 2.

En términos comparativos, si bien entre 2001 y 2010 puede advertirse una disminución en las brechas entre las chances de no asistencia en hogares con jefes con estudios terciarios o universitarios en comparación con hogares con jefes con instrucción primaria, esta disminución de 4,874 veces a 4,367 veces no permite reconocer una diferencia relevante (en términos de reducción de la desigualdad social) en la situación de dichos hogares. Asimismo, al observarse por estrato la evolución 2001-2010, algunos factores como la jefatura femenina y la desocupación del jefe han pasado de tener una influencia moderada en el año 2001 (en el estrato 2) a no tener una influencia significativa en el año 2010.

De igual manera, la influencia del contexto residencial —el clima de no asistencia en el radio- ha sido escasa en los estratos más bajos mientras que en el estrato 4 llega a 1,97 veces.

\section{Variables de control de nivel individual}

El modelo de regresión (para las personas de entre 13 a 21 años) para el año 2010 muestra como significativos a la edad y al sexo - los varones tienen 1,58 veces las chances de las mujeres de abandonar-y a la edad — por cada año adicional (tomando 
la situación de quien tiene 13 años como base) las chances se incrementan en 17,3\% $(\operatorname{Exp}(B)=1,173, \operatorname{Sig}<0,001)$ por cada año adicional en la edad de la persona-.

Figura 3. Coeficientes $\operatorname{Exp}(B)$ de modelos de regresión logística sobre población total (general) y por estrato. CABA. Años 2001-2010

\begin{tabular}{|c|c|c|c|c|c|c|c|c|c|c|}
\hline \multirow{4}{*}{ No asistencia escolar* } & \multicolumn{10}{|c|}{ Modelos } \\
\hline & \multicolumn{2}{|c|}{ General } & \multirow{2}{*}{\multicolumn{4}{|c|}{$\frac{2001}{\text { Estrato }}$}} & \multirow{2}{*}{\multicolumn{4}{|c|}{$\frac{2010}{\text { Estrato }}$}} \\
\hline & \multirow{2}{*}{2001} & \multirow{2}{*}{2010} & & & & & & & & \\
\hline & & & E1 & E2 & E3 & E4 & E1 & E2 & E3 & E4 \\
\hline & $\operatorname{Exp}(B)$ & $\operatorname{Exp}(B)$ & $\operatorname{Exp}(B)$ & $\operatorname{Exp}(B)$ & $\operatorname{Exp}(B)$ & $\operatorname{Exp}(B)$ & $\operatorname{Exp}(B)$ & $\operatorname{Exp}(B)$ & $\operatorname{Exp}(B)$ & $\operatorname{Exp}(B)$ \\
\hline \multicolumn{11}{|l|}{ Individual } \\
\hline Género (varón) & 1,753 & 1,58 & 1,157 & 1,835 & 1,928 & 1,615 & 1,35 & 1,481 & 1,713 & 1,578 \\
\hline Edad & 1,174 & 1,173 & 1,277 & 1,185 & 1,132 & 1,098 & 1,286 & 1,231 & 1,142 & $1,036^{* *}$ \\
\hline \multicolumn{11}{|l|}{ Condición de actividad (referencia=inactivo) } \\
\hline - Ocupado & 3,058 & 2,345 & 3,184 & 2,862 & 3,103 & 3,49 & 2,06 & 2,043 & 2,409 & 2,8 \\
\hline - Desocupado & 2,724 & 2,228 & 2,728 & 2,606 & 2,654 & 2,644 & 2,009 & 2,242 & 2,116 & 2,754 \\
\hline \multicolumn{11}{|l|}{$\begin{array}{l}\text { Relación con la jefatura de hogar (referencia }=\text { hijo o } \\
\text { nieto) }\end{array}$} \\
\hline - Es el jefe & 1,701 & 1,704 & 2,937 & 2,418 & 1,414 & - & 2,541 & 2,506 & 1,607 & $1,296^{* *}$ \\
\hline - Conyuge o pareja & 5,657 & 4,324 & 6,207 & 6,083 & 5,001 & 5,575 & 5,269 & 4,561 & 3,981 & 4,524 \\
\hline - Yerno o nuera & 5,166 & 3,641 & 6,287 & 4,788 & 4,577 & 5,951 & 3,201 & 3,54 & 3,56 & 3,602 \\
\hline - Servicio domestico & 25,058 & 12,713 & - & 16,085 & 28,127 & 49,946 & $10,676^{* * *}$ & 11,051 & 9,594 & 19,475 \\
\hline - Otros (familiares y no familiares) & 2,393 & 1,943 & 2,746 & 2,655 & 2,263 & 2,242 & 2,71 & 2,211 & 1,878 & 1,465 \\
\hline \multicolumn{11}{|l|}{$\begin{array}{l}\text { Estructura y situación socioeconómica del hogar } \\
\text { Educación del jefe (referencia=terciaria, } \\
\text { universitaria o más) }\end{array}$} \\
\hline - Sin instrucción & 4,874 & 4,367 & 4,015 & 4,161 & 4,956 & 6,018 & 2,783 & 3,13 & 4,294 & 4,843 \\
\hline - Primaria & 3,928 & 3,822 & 3,191 & 3,17 & 3,789 & 4,276 & 2,27 & 2,692 & 3,448 & 4,113 \\
\hline - Secundaria & 1,187 & 1,234 & - & 1,266 & - & - & - & - & 1,205 & - \\
\hline Niños $<=5$ años en el hogar & 2,185 & 1,798 & 1,536 & 2,11 & 2,495 & 2,358 & 1,398 & 1,599 & 1,93 & 2,398 \\
\hline Jefatura femenina & 1,107 & 1,131 & - & $1,098 * *$ & 1,127 & - & - & - & 1,162 & 1,221 \\
\hline Hogar monoparental & 1,141 & 1,108 & 1,249 & 1,218 & 1,109 ** & - & - & 1,29 & 1,163 & - \\
\hline Hay adultos inactivos en el hogar & 1,234 & 1,197 & 1,249 & 1,26 & 1,195 & 1,326 & 1,209 & 1,227 & 1,207 & 1,243 \\
\hline Jefe desocupado & - & 0,841 & - & $1,079 * * *$ & - & - & - & - & - & 0,586 \\
\hline Jefe inactivo & - & 0,909 & $1,193^{* *}$ & - & - & 0,638 & - & - & - &, $800 * *$ \\
\hline \multicolumn{11}{|l|}{ Condiciones materiales (hábitat, bienes y servicios) } \\
\hline Ausencia de cañería de agua en la vivienda & 1,307 & 1,196 & $1,202^{* *}$ & $1,189 * *$ & $1,215^{* *}$ & - & $1,152 * *$ & - & $1,166^{* *}$ & $1,602 * *$ \\
\hline Ausencia de cielorraso & - & - & - & $1,115^{* *}$ & 1,302 & - & - & - & $1,095^{* * *}$ & - \\
\hline No hay computadora en el hogar & 2,402 & 1,89 & 2,174 & 2,261 & 2,247 & 2,376 & 1,631 & 1,6 & 1,931 & 2,397 \\
\hline No se dispone de gas de red & 1,209 &, $939 * *$ & - & 1,371 & 1,427 & - & - & - & 1,182 & - \\
\hline No se posee heladera & 1,617 & 1,313 & 1,308 & 1,528 & 1,852 & 2,718 & 1,267 & - & 1,236 & 1,835 \\
\hline No propietario de vivienda y terreno & 1,366 & 1,178 & - & 1,494 & 1,387 & 1,423 & - & 1,171 & 1,19 & $1,140 * *$ \\
\hline \multicolumn{11}{|l|}{ Contexto residencial } \\
\hline $\begin{array}{l}\text { Proporción de jóvenes en situación de no asistencia } \\
\text { escolar en el radio ( } 13 \text { a } 18 \text { años) }\end{array}$ & 1,073 & 1,103 & 1,071 & 1,085 & 1,461 & 2,304 & 1,073 & 1,086 & 1,39 & 1,974 \\
\hline
\end{tabular}

Fuente: elaboración propia en base a datos del CNPHyV 2001 y CNPHyV 2010.

* Los valores sin indicación (** o ***) son aquellos mostraron todos Sig. $<0,001$. Los valores de $\operatorname{Exp}(\mathrm{B})$ con $\mathrm{Sig}>=0,010$ fueron omitidos en la tabla (‘- $)$. ** Sig. $<0,005 ; * * *$ Sig. $<0,010$. 


\section{Variables de control para las dimensiones materiales}

Del conjunto de indicadores evaluados para el año 2010 respecto de las condiciones materiales, los más influyentes en las chances de continuidad escolar fueron la tenencia de computadora y la tenencia de heladera, con 1,890 veces y 1,313 veces, respectivamente, en relación a quienes sí las tenían. En segundo lugar aparecen luego los elementos propios de la vivienda, tales como la no disponibilidad de instalación de agua y el régimen de tenencia más inestable (no ser dueño de la vivienda y del terreno), con $19,6 \%$ y $17,8 \%$ de mayores chances de no asistencia respectivamente respecto de quienes no presentaban estas características.

Con relación al año 2001, los indicadores de condiciones materiales evidenciaron bajas moderadas en sus dependencias. En el estrato educativamente más alto (E4) para el año 2010 comienza a ser relevante la instalación de cañería de agua en la vivienda, posiblemente dando cuenta de una mayor heterogeneidad en las condiciones de hábitat de los barrios con prevalencia de nivel universitario. Cabe señalar que en el estrato 2 (prevalencia de primaria completa) tanto la tenencia de heladera como la disponibilidad de cañerías de agua aparecen como no significativas para la predicción de chances de no asistencia en dicho segmento, manteniéndose sin embargo el uso de computadora y el régimen de tenencia como criterios relevantes.

\section{CONCLUSIONES}

A modo de conclusión, es posible retomar la hipótesis inicial de este texto para ser evaluada a la luz de los resultados obtenidos.

Como hemos podido ver, las tramas de relaciones no son una imagen mecánica de otros aspectos socioeconómicos o habitacionales, y por el contrario, han mostrado influir de manera marcada en las posibilidades de continuidad de la formación educativa.

De este modo, incluso si ciertos tipos de interacción pueden ser más frecuentes en unos contextos que en otros, el análisis empírico permitió mostrar que existe un alto grado de dependencia de las trayectorias educativas de las personas con el abanico de relaciones y participaciones que tienen y sostienen.

Consecuentemente, si bien, por ejemplo, el nivel educativo del jefe de hogar puede estar correlacionado parcialmente en la Ciudad de Buenos Aires con la calidad constructiva de la vivienda, la influencia en la tasa de escolarización de ambos factores fue independiente. Más precisamente, carencias materiales de alto impacto como la ausencia de instalación de cañerías de agua y de gas de red en la vivienda han mostrado un efecto menor en la escolarización (ambas combinadas) que el vivir con un jefe de hogar sin secundaria completa.

A partir de la información censal analizada se ha podido caracterizar la no asistencia escolar en el ámbito de la Ciudad de Buenos Aires en el período 2001-2010 en términos de contextos relacionales personales. En dicho proceso, algunos elementos 
esperables se han podido constatar, tales como el mayor nivel de exclusión educativa al avanzarse en la edad (fenómeno referido en la literatura como "desgranamiento"), el estar más vinculados los jóvenes con el mercado de trabajo, así como una incidencia más grande del fenómeno entre varones que entre mujeres.

Al mismo tiempo, han emergido algunos elementos menos previsibles en dicha caracterización. Ejemplo de esto lo es el hecho de que, considerando los barrios por la prevalencia de educación de sus jefes, la influencia del género y la ocupación del alumno condicionaban en mayor medida hacia la exclusión escolar en zonas con prevalencia de jefes con estudios secundarios y universitarios que en zonas con jefes de menores niveles educativos.

También dentro de este grupo de hallazgos, el rol dentro del hogar ha mostrado niveles muy altos de condicionalidad de las chances de no asistencia, constituyendo un factor que debería ser observado con atención en términos de focalización de esta problemática, ya no solamente en términos de ser "jefe de hogar", sino también por las situaciones diferenciadas observadas en quienes son cónyuges de estos jóvenes jefes, o para quienes cohabitan con los padres de sus parejas.

Asimismo, se ha hecho visible la situación extrema de las personas ocupadas en empleo doméstico sin retiro (con cama), quienes acumularon los peores indicadores en términos de chances de completar los estudios secundarios, llegando a estar en 2010 el estrato 4 en una relación de 19 a 1 con las chances de los jóvenes con los que comparten el barrio de residencia.

La presencia de niños pequeños en los hogares constituyó también un factor que marcó las chances de continuidad escolar, con fuerza en los estratos bajos, aumentando un $40 \%$ las chances de no asistencia, pero más especialmente en los estratos de más alto nivel educativo, donde hacían crecer en un $240 \%$ dichas chances.

En términos agregados, y en comparación con las condicionalidades derivadas de la posición relacional (como el convivir con los suegros o tener por jefe a una persona con pocos estudios), los datos respecto de la influencia de las condiciones materiales fueron consistentes con la poca elasticidad ocurrida entre la mejora de las condiciones materiales en la década observada y el comportamiento de la inclusión educativa.

Asimismo, los modelos de regresión logística han servido para mostrar una baja en la condicionalidad de la no asistencia principalmente en los factores utilizados como control a nivel individual y de las condiciones materiales, si bien en ambos casos las chances de quienes están en las categorías más favorecidas continúan siendo muy superiores a aquellas que tienen más comprometida su continuidad escolar.

A modo de conclusión, cabría afirmar que el problema de la exclusión escolar está en la escuela, y no en la casa. La diversidad de los hogares se mantiene como un desafío no resuelto para una escuela que no alcanza a retener a quienes afrontan sus vidas con grandes responsabilidades: quienes trabajan, quienes son padres, quienes cuidan a sus mayores. 
Poder ampliar el campo de soluciones que ofrece la escuela media podría estar ligado, al menos parcialmente, a ver con más claridad las relaciones interpersonales de los jóvenes que asisten y buscan allí una formación, y en poder tratar esas capacidades y condicionantes derivados de sus situaciones vinculares de maneras más apropiadas a las necesidades y motivaciones que aportan a la práctica educativa.

\section{REFERENCIAS}

Arancibia, V. (1995). Factores que afectan el rendimiento escolar de los pobres: revisión de investigaciones educacionales, 1980-1995. En E. Cohen (Ed.), Educación, eficiencia y equidad (pp. 157-213). Santiago, Chile: CEPAL/OEA/Ediciones Sur.

Binstock, G., y Cerruti, M. (2005). Carreras truncadas. El abandono escolar en el nivel medio en la Argentina. Buenos Aires, Argentina: Unicef.

Briscioli, B., y Toscano, A. (2012). La escolarización secundaria obligatoria. Dos estudios sobre políticas destinadas al reingreso de adolescentes y jóvenes a la escuela en Argentina. Presentada en Seminario Internacional: Políticas, Sujetos y Movimientos Sociales en el Nuevo Escenario Latinoamericano, 16 y 17 de julio, CLACSO, Santiago de Chile.

Bourdieu, P. (2013). La nobleza de estado: educación de elite y espíritu de cuerpo. Buenos Aires, Argentina: Siglo XXI.

Canevari, J., Catalá, C., y Montes, N. (2011). La educación secundaria en la Ciudad de Buenos Aires. Dinámica de la matrícula y desafíos institucionales para la inclusión. Informes de investigación de la dirección de investigación y estadística del Ministerio de Educación del GCBA. Buenos Aires, Argentina: Ministerio de Educación del Gobierno de la Ciudad de Buenos Aires.

Comisión Económica para América Latina y el Caribe. (2002). Panorama Social de América Latina 2001 2002. Santiago, Chile: Naciones Unidas.

Con, M. (2010). Perfiles de abandono escolar en la Ciudad de Buenos Aires, en el nivel secundario, para los años 2004 y 2008. Informes de investigación de la dirección de investigación y estadística del ministerio de educación del GCBA. Buenos Aires, Argentina: Dirección de Investigación y Estadística, Ministerio de Educación.

Cubillos Romo, J. (2017). Maternidad adolescente, entre la escolarización y el fracaso escolar. Actualidades Investigativas en Educación, 17(1), 1-22.

De Grande, P. (2016). El formato Redatam. Estudios demográficos y urbanos, 31-3(93), 811-832.

De Grande, P., y Salvia, A. (2008). Segregación residencial socioeconómica y espacio social: deserción escolar de los jóvenes en el área metropolitana de Gran Buenos Aires. En A. Salvia (Comp.), Jóvenes promesas. Trabajo, educación y exclusión social de jóvenes pobres en la Argentina (pp. 61-88). Buenos Aires, Argentina: Miño y Dávila.

Del Bono, A., Mallimaci Barral, A., Cabrera, N., Bulloni Yaquinta, M., y Saavedra, L. (2017). Maternidad y paternidad adolescente. El derecho a la educación secundaria. Buenos Aires, Argentina: Unicef. 
Di Pietro, S., Tófalo, A., Medela, P., y Pitton, E. (2014). La oferta de educación primaria y la trayectoria de los estudiantes en la Ciudad de Buenos Aires: logros de la última década y persistencia de desigualdades. Población de Buenos Aires, 19, 7-27.

Di Virgilio, M., Marcos, M., y Mera, G. (2015). Las ciudades dentro de la ciudad: características sociodemográficas y habitacionales de la Ciudad de Buenos Aires según sus tipos de hábitat. Población de Buenos Aires, 12(22), 33-57.

Dussel, I. (2004). Desigualdades sociales y desigualdades escolares en la Argentina de hoy. Algunas reflexiones y propuestas. Buenos Aires, Argentina: FLACSO.

ESRI. (2011). ArcGIS Desktop: Release 10. Redlands, CA: Environmental Systems Research Institute.

Fainsod, P. (2008). Embarazo y maternidad adolescente en la escuela media. Buenos Aires, Argentina: Miño y Dávila.

Ferreyra, H., Vidales, S., Kowadlo, M., y Bono, L. (2013). Hacia la educación secundaria obligatoria. Notas del proceso en la República Argentina. Actualidades Investigativas en Educación, 13(2), 1-29.

Fiszbein, A., Giovagnoli, P., y Adúriz I. (2003). El impacto de la crisis argentina en el bienestar de los hogares. Revista de la CEPAL, 79, 151-167.

Gigli Box, M. (2014). Jano conectado: las dos caras de las netbooks del estado. Question, 1(42), 85-96.

Groisman, F. (2012). Determinantes de la escolarización y participación económica de los adolescentes en Argentina (2004-2009). Frontera norte, 24(48), 37-61.

IBM. (2012). IBM SPSS Statistics for Windows, Version 21.0. Armonk, NY: IBM Corp.

Instituto Nacional de Estadística y Censos. (15 de julio de 2016). Información de interés público sobre el Censo Nacional de Población, Hogares y Viviendas 2010. Recuperado de https://www.indec.gov.ar/gacetillasdeprensa_detalle.asp?id=107

Isola, N. (2014). El envilecimiento de las cifras. Una mirada moderna sobre el INDEC y los Operativos Nacionales de Evaluación en la Argentina en el siglo XXI. Avaliação e Políticas Públicas em Educação, 22(83), 295-319.

Kessler, G. (2002). La experiencia escolar fragmentada. Estudiantes y docentes en la escuela media en Buenos Aires. Buenos Aires, Argentina: IIPE - Unesco Sede Regional Buenos Aires.

Krichesky, M. (2010). Políticas de inclusión y gestión educativa en escuelas medias en contextos de alta vulnerabilidad. Informes de investigación de la dirección de investigación y estadística del Ministerio de Educación del GCBA. Buenos Aires, Argentina: Ministerio de Educación del Gobierno de la Ciudad de Buenos Aires.

Lindenboim, J. (2011). Las estadísticas oficiales en Argentina ¿Herramientas u obstáculos para las ciencias sociales?. Trabajo y Sociedad, 16(15), 19 a 38.

Molinatti, F. (2017). Las migraciones internas en Argentina: posibilidades, alcances y desafíos para su captación mediante el Censo 2010. Presentado en XIV Jornadas Argentinas de Estudios de Población, 21-22 de septiembre, Santa Fé, Argentina. 
Nobile, M. (2016). Los egresados de las Escuelas de Reingreso: sobre los soportes mínimos para aprovechar una política de reinserción educativa. Espacios en blanco. Serie indagaciones, 26(2), 187-210.

Programa de las Naciones Unidas para el Desarrollo. (2009). Abandono escolar y políticas de inclusión en la educación secundaria. Buenos Aires, Argentina: Programa de las Naciones Unidas para el Desarrollo.

Polack, M. E. (19 de junio de 2014). Adultos: sin excusas para no terminar la escuela secundaria. La Nación. Recuperado de https://www.lanacion.com.ar/1702572-adultos-sin-excusas-para-noterminar-la-escuela-secundariai

Rodríguez, F. (2009). Notas sobre los conceptos de los "Nuevos Asentamientos Urbanos" (NAUs) en la ciudad de Buenos Aires. Pampa: Revista Interuniversitaria de Estudios Territoriales, 5, 197-218.

Román, M. (2009). Abandono y Deserción Escolar: duras evidencias de la incapacidad de retención de los sistemas y de su porfiada inequidad. Revista Iberoamericana sobre Calidad, Eficacia y Cambio en Educación, 7(4), 3.9.

TECHO. (2013). Relevamiento de asentamientos informales 2013. Buenos Aires, Argentina: TECHO Argentina.

Tedesco, J., y López, H. (2002). Desafíos a la educación secundaria en América Latina. Revista de la CEPAL, 76, 55-69. 